\title{
The Teacher Anxiety Scale: The Study of Validity and Reliability
}

\section{Dr. Ornela Bilali}

\author{
"A. Xhuvani" University, Faculty of Education, Elbasan, Albania. \\ E-mail: ornelabilali@gmail.com
}

Doi:10.5901/jesr.2014.v4n2p90

\begin{abstract}
Teaching Anxiety Scale developed by Parsons (1973) is still considered the most effective way of measuring Teaching Anxiety, for both pre-service and in-service teachers. The purpose of the present study was to explore the validity and reliability of the Albanian version, of the Teaching Anxiety Scale applied to student teachers. Data in this study were collected from a total number of 92 students enrolled in the third year of the Bachelor study program: "Elementary Teacher" and "Preschool Teacher". Measurements were made at two stages of development Pedagogical Practice. Descriptive statistics, principal component with varimax factor analysis, and Scree Test were used to explore the data analyses. Results revealed that the Albanian version of the Teaching Anxiety Scale had high reliability coefficient which was $\alpha=.97$ (before practice) and $\alpha=.95$ (after practice), as estimated by Cronbach alpha coefficient. Factorial analysis found that, items of the teaching anxiety scale yielded a single factor with an eigenvalue of 16.52 and the unifactor solution accounted for $57 \%$ of the total variance.
\end{abstract}

Keyword: Teaching Anxiety Scale, Teaching Anxiety, Student teachers, Validity, Reliability.

\section{Introduction and Theoretical Framework}

Considerable evidence exists that anxiety can impair performance in a variety of tasks. It suspected that this evidence extends to impairment of teaching performance as well. Teaching Anxiety Scale (TCHAS) was designed by Parsons (1973), to provide a tool for measuring anxiety specific to the task of teaching. Although it was designed in 1973 is regarded today as the most effective way to measure teaching anxiety. Many researchers as: Cheung \& Hui (2011), AlMehrzi, Al-Busaidi, Ambusaidi, Osman, Amat \& Al-Ghafri (2011), Woullard (2003), Pigge \& Marso (1997), Williams (1991), have applied the Teaching Anxiety Scale, TCHAS - Parsons (1973), as a measuring instrument in their studies.

This instrument is available:

$\checkmark$ On the Internet: http://www.eric.ed.gov/contentdelivery/servlet/ERICServlet?accno=ED079330

$\checkmark$ Or in the book of: Lester, P.E. \& Bishop L.K. (2001.) Handbook of Tests and Measurement in Education and the Social Sciences. $2^{\text {nd }} e d$.

The TCHAS contains a variety of self-report statement about teacher reactions to teaching. These reactions are two general kinds: first, emotional responses to a variety of different situations related to teaching, and second, attitudes toward teaching as a profession. 1

Parsons (1973) reports that:

"Extensive testing of the scale shows that (1) the TCHAS is a measure of teaching anxiety; (2) that the TCHAS measures reliably some quality distinct from what either the Manifest Anxiety Scale (MAS) or Test Anxiety Scale (TAS) measures; (3) that the TCHAS is stable (.95) over short periods of time; (4) that the validity of the TCHAS is not merely an artifact of similarities in method measurement; (5) that pre-service teacher responses teachers as observed and interpreted by their teaching supervisors; (6) that teaching anxiety as measured by the TCHAS is a unitary variable, and (7) that over several studies, anxiety as measured by the TCHAS consistently decreases as experience in teaching increases" (p. 21).

1 Parsons, J. (1973). Assessment of anxiety about teaching using the Teaching Anxiety Scale: Manual and research report. The research and development center for teacher Education University of Texas. Paper presented at Annual Meeting of American Educational Research Association, New Orleans. Louisiana 


\subsection{Teaching Anxiety Scale}

The TCHAS was developed initially at Stanford University in two equivalent forms TCHAS (1) -25 and TCHAS (2) -25 for use with pre-service, intern teacher. More recently, several slightly altered versions of the TCHAS (TCHAS (1)-24, TCHAS (1)-28, and TCHAS (1)-29) were made available for use. An attempt to increase the appropriateness of the TCHAS content for the study of in-service teacher resulted in the addition of three slightly altered version: TCHAS (1)-24, which is TCHAS (1)-25 minus item 16; TCHAS (1)-28, which is TCHAS (1)-24 plus four item; and TCHAS (1)-29 which is a composite of all items in TCHAS (1)-25 and TCHAS (1)-28. TCHAS (1)-29 has an advantage of being scored in a number of ways, depending upon the kind of teacher.

Since, on all forms of TCHAS, all the statements are presented with a 1-5 choice option format, from low agreement with an item ( $1=$ "never") to high agreement with an item ( 5 = "always"). Other middle -range options are "infrequently", "occasionally" and "frequently" 2- 4 respectively. Approximately half of the items are phrased negatively (in terms of admission of anxiety); for examples: "I'm worried whether I can be a good teacher." A high degree of agreement with this negatively phrased item is scored "high anxious". The other items are positively phrased, for example: "I feel sure I can be a good teacher." A high degree of agreement with positively phrased items is scored "low anxious" (Parsons, 1973:1)

Approximately half of items are phrased positively and half are phrased negatively, reverse scoring of positively phrased item responses is used in order procedure item score with consistent meaning. After reverse scoring has been performed, a high score on all items reflects a high degree of admitted anxiety. Reverse scoring is accomplish by the following procedure: "1' s" are rescored "5' s"; "2' s" are rescored "4' s"; "3' s" remain the same; "4's" are rescored "2' s"; and " 5 ' $\mathrm{s}$ " are rescored " 1 ' $\mathrm{s}$ ". The total TCHAS scale score is then calculate by summing the item scores.

\subsection{Reliability and Validity of Teaching Anxiety Scale (Parsons, 1973)}

All the alpha coefficients indicated that the internal consistency of TCHAS is high from .87 to 0.94 . Confirmation of this high internal consistency was provided by Gregory (1976) 2 who reported reliability measures of .87 and .86 for samples of 520 and 401 student teachers (p. 207). If so William Tattersall (1979) used the teaching anxiety scale, and resulted that TCHAS (Parson, 1973) had internal consistency as pre test (.87) and post-test (.91).

A factor analysis was done on the TCHAS by Parson. The items for the teaching anxiety were subjected to principal-components factor analysis to determine whether they represented a single construct. These items yielded a single factor with an eigenvalue of 4.20 and the unifactor solution accounted for $30 \%$ of the total variance. All items loaded between 0.27 and 0.72 with a mean of 0.53 on the factor, thus TCHAS results with the single factor structure. A similar single-factor structure was found by other studies (Albusaidi \& Aldhafri, 2009).

\section{Method}

\subsection{Participant}

The sample of this study consisted of 92 students enrolled in the third year of the Bachelor study program: "Elementary Teacher" and "Preschool Teacher". $95 \%$ are female and 5\% are male. $84 \%$ of the samples are at the age of $22.60 \%$ are students in Elementary Teacher program study and 40\% are students in Preschool Teacher program study.

\subsection{Procedures}

Since TCHAS is not used in any similar study in Albania, and the source in the literature is available in English translation and adaptation was used in Albanian. After the translation process, which was made by a lecturer of English at the University, was taken expert opinion on the validity of the content.

Measurements were made at two stages of development Pedagogical Practice, at the end of serial practice and the end of 8-week practice.

2 Gregory, A. (1976), The effect of student teaching on the professional self-concept of student teachers - A study of student teachers in the professional program, Simon Fraser University. 


\subsection{Data analysis}

The collected data were analyzed using Statistical Package for Social Sciences (SPSS), version $17^{\text {th }}$ software. TCHAS reliability was evaluated using Cronbach's alpha and the internal consistency. For the structure validity of the scale, principal axis factor analysis with varimax rotations and Screen Test was used.

\section{Results and Discussion}

\subsection{Reliability analysis of the TCHAS}

Reliability is the degree of compliance that provides instrument with participants. To assess the reliability of Teaching Anxiety Scale was used Cronbach's alpha. Coefficient Cronbach's alpha is used to assess the reliability of the instrument as a whole and to test the reliability score for each category, but not for dichotomous responses. TCHAS complements this condition. Each item on the Teaching Anxiety Scale requires a response by choosing a level of five choices ( 1 for "never", 2 for "infrequently", 3 for "occasionally", 4 for "frequently", 5 for "always").

The Teaching Anxiety Scale have resulted in a high coefficient of reliability, as before practice $(\alpha=.97)$, and after performing pedagogical practice $(a=.95)$. Henson $(2001 b)$, has recommended that for general research purposes, reliability should be at least 0.80 . According to Field (2005), this is a good level of internal consistency.

Table 1: Results of Cronbach's alpha coefficient

\begin{tabular}{l}
\hline Before practice After practice \\
\hline TCHAS .97 .95 \\
\hline
\end{tabular}

By inspection of the item correlations containing TCHAS, it was concluded that there is no correlation under .30 and correlations generally ranging by moderate to strong (see Table 2).

Table 2. The correlations between the 29 items of TCHAS

\begin{tabular}{|c|c|c|c|c|c|c|c|c|c|c|c|c|c|c|c|c|c|c|c|c|c|c|c|c|c|c|c|c|}
\hline & 1 & 2 & 3 & 4 & 5 & 6 & 7 & 8 & 9 & 10 & 11 & 12 & 13 & 14 & 15 & 16 & 17 & 18 & 19 & 20 & 21 & 22 & 23 & 24 & 25 & 26 & 27 & $28 \quad 29$ \\
\hline 1 & 1 & & & & & & & & & & & & & & & & & & & & & & & & & & & \\
\hline 2 & $739^{\circ}$ & 1 & & & & & & & & & & & & & & & & & & & & & & & & & & \\
\hline 3 & $.457^{*}$ & $306^{*}$ & 1 & & & & & & & & & & & & & & & & & & & & & & & & & \\
\hline 4 & , $478^{+4}$ & $413^{*}$ &, $586^{*}$ & 1 & & & & & & & & & & & & & & & & & & & & & & & & \\
\hline 5 & $562^{4}$ & $593^{*}$ & $510^{*}$ &, $391^{n}$ & 1 & & & & & & & & & & & & & & & & & & & & & & & \\
\hline 6 &, $552^{*}$ & $574^{*}$ & $478^{*}$ & $t, 519^{*}$ & $717^{*}$ & 1 & & & & & & & & & & & & & & & & & & & & & & \\
\hline 7 & $535^{+}$ & $498^{* 4}$ & $394^{*}$ & *,417" & $722^{* 4}$ & $708^{*}$ & 象 1 & & & & & & & & & & & & & & & & & & & & & \\
\hline 8 &, $5666^{+1}$ & $557^{*}$ &, $435^{*}$ & $7,530^{+4}$ & $691^{*}$ & $7,722^{*}$ & $4,835^{*}$ & 1 & & & & & & & & & & & & & & & & & & & & \\
\hline 9 & ,634" & $583^{*}$ & $436^{*}$ & $4,488^{+4}$ & $676^{4}$ & $684^{*}$ & , $794^{*}$ & $872^{4}$ & 1 & & & & & & & & & & & & & & & & & & & \\
\hline 10 & ,611 & $613^{*}$ &, $418^{*}$ & ", 467" & $625^{*}$ & $673^{*}$ & $4,730^{*}$ & $7993^{*}$ &, $919 *$ & 1 & & & & & & & & & & & & & & & & & & \\
\hline 11 . & $623^{\prime \prime}$ & ,541" &, $464^{* *}$ & $4,542^{4}$ & $601^{*}$ & $612^{*}$ & $4,617^{*}$ & $694^{*}$ &, $681^{* *}$, & $701^{*}$ & 1 & & & & & & & & & & & & & & & & & \\
\hline 12 & $606^{*}$ & 562 &, $534^{*}$ & $t, 491^{*}$ & $599^{*}$ &, $598^{*}$ & $4,588^{*}$ & $654^{*}$ &, $680^{*}$ &, $683^{\circ}$ & $.787^{*}$ & 1 & & & & & & & & & & & & & & & & \\
\hline 13 & $675^{4}$ & $574^{*}$ &, $481^{*}$ &, $575^{+4}$ & $624^{*}$ & $644^{*}$ & $4,619^{4}$ & $658^{*}$ &, $709^{* *}$ & $690^{\circ}$ & $775^{4}$ & $764^{* x}$ & 1 & & & & & & & & & & & & & & & \\
\hline 14. & $615^{*}$ &, $553 *$ &, $497^{*}$ & *,595" & $614^{*}$ & $625^{*}$ & ". $516^{*}$ & $6,620^{*}$ & $1,605^{*}$ &, $558^{*}$ & $681^{*}$ &, $738^{* *}$ & $4,831^{4}$ & 1 & & & & & & & & & & & & & & \\
\hline 15 & $638^{+4}$ &, $505^{*}$ &, $525^{*}$ & $\nexists, 537^{*}$ &, $559=$ & $7555^{*}$ & $", 577^{\star \prime}$ & $655^{*}$ & $1,659^{* *}$ & $620^{\circ}$ & 689 & $715^{*}$ & $4,769^{4+4}$ & $1,750^{*}$ & 1 & & & & & & & & & & & & & \\
\hline 16 , &, $614^{*}$ & $569^{*}$ &, $484^{*}$ & $", 589^{*}$ & $601^{*}$ & $638^{*}$ & " & $6667^{*}$ & $680^{*}$ &, $665^{\circ}$ & $695^{*}$ & $758^{*}$ & $4,813^{m}$ & $770^{*}$ & $7,751^{*+}$ & 1 & & & & & & & & & & & & \\
\hline 17 &, 576 & $534^{*}$ & ,481* & *,, $552^{4}$ & $515^{\circ}$ &, $580^{*}$ & $n, 514^{*}$ & $629^{*}$ &, $619^{*}$ & $648^{\circ}$ & $681^{*}$ &, $703^{*}$ & $n, 769^{*}$ & $.717^{*}$ & $=, 692^{*}$ &, $865^{*}$ & 1 & & & & & & & & & & & \\
\hline 18 & ,531" & $547^{*}$ &, $407^{*}$ & $t, 554^{*}$ & $446^{*}$ &, $554^{*}$ & $n, 492^{n+4}$ & $568^{*}$ & $1,532^{*}$ &, $575^{5}$ &, $584^{*}$ & $648^{*}$ & $n, 695^{4}$ &., $639^{*}$ &, $563^{*}$, & ,808" &, $840^{*}$ & 1 & & & & & & & & & & \\
\hline 19 &, $522^{4}$ & $514^{*}$ &, $419^{*}$ &, $424^{*}$ & $465^{*}$ &, $565^{*}$ & $n, 544^{*}$ &, $544^{*}$ &, $524^{* *}$, &, $535^{\circ}$ & $2,599^{*}$ & $641^{*}$ & ${ }^{* 1}, 640^{\circ}$ & $7,612^{*}$ &, $576^{*}$ &, $721^{4}$ & $727^{4}$ &, $742+$ & 1 & & & & & & & & & \\
\hline 20 , &, $598^{+4}$ & $585^{\circ}$ &, $400^{*}$ & $t, 560^{+*}$ & $460^{\circ}$ & $.513^{*}$ & $n, 509^{n+4}$ & $572^{*}$ &, $579 *$ &, $597^{7}$ & $.598^{*}$ &, $591^{*}$ & ${ }^{* 1}, 694^{4}$ & ",589" & $1,603^{*}$ &, $774^{4}$ & $805^{\circ}$ &, $786^{+\infty}$ & $739^{4}$ & 1 & & & & & & & & \\
\hline 21 &, 476 & $514^{*}$ &, $389^{*}$ & $7,559^{*+}$ & $407^{*}$ & $4,469^{*}$ & $4,468^{*}$ & $468^{*}$ &, $496^{*}$ &, $458^{\circ}$ &, $504^{*}$ &, $573^{*}$ & ${ }^{*}, 639^{*}$ & $\mid, 562^{*}$ & $4,475^{*}$ & ",633" & $658^{\circ}$ &, $674^{*}$ &, 562 & $650^{*}$ & 1 & & & & & & & \\
\hline 22 & $.373^{*}$ &, $251^{*}$ &, $400^{*}$ & $\star, 349^{*}$ &, $283^{*}$ & $280^{*}$ & " $279^{* 4}$ & $\mid, 383^{*}$ &, $330^{*}$ &, $310^{\circ}$ & 374 &, $381^{*}$ & ${ }^{*} \mid, 426^{*+4}$ & $4,407^{* 4}$ & $*^{*}, 471^{*}$ & 1,545 &, $543^{*}$ &, $555^{*}$ &, $438^{4}$ & $472 *$ &, $514^{*}$ & 1 & & & & & & \\
\hline 23 &, $547^{*}$ &, $448^{*}$ &, $313^{*}$ & *,, $537^{*}$ & 332 & $1,469 *$ & $n, 493^{*}$ &, $517^{*}$ & $570^{*}$ &, $557^{*}$ & $481^{*}$ & $597 *$ & ${ }^{* *}, 639^{*}$ & $\mid, 586$ &,$+ 550^{*}$ & $", 611^{*}$ & $635^{\circ}$ & $6,674^{*}$, &, 612 & $673^{*}$ & $6,611^{*}$ & 299 & 1 & & & & & \\
\hline 24 & $.491^{*}$ & $434^{*}$ & $377^{*}$ &, $456^{4+}$ & $372^{*}$ & $355^{*}$ &, $352^{4}$ & $404^{*}$ & $4,410^{*}$ &, $410^{\circ}$ & $560^{*}$ &, $580^{*}$ & ${ }^{*}, 644^{4}$ &., $572^{*}$ & $4,480^{*}$ &, $638^{*}$ & $682^{2}$ & $1,694^{*+1}$, &, $624^{*}$ & $651^{*}$ & $.646^{*}$ & 469 & $538^{*}$ & 1 & & & & \\
\hline 25 & , 481" & $457^{*}$ &, $365^{*}$ & ",451* & $467^{*}$ & ,481* & $4,469^{* 4}$ & $521^{*}$ &, $546^{*}$ &, $518^{n}$ & $537^{*}$ &, 539 & $", 618^{4}$ & ,549" & $4,496^{*}$ & 7,719 & $633^{*}$ & $1,677^{*+1}$ &, $628^{4}$ & $737^{4}$ & $609^{*}$ &, $474^{4}$ &, $522^{*}$ &, $663^{* 4}$ & 1 & & & \\
\hline 26 , & $391^{*}$ & $306^{*}$ &, $327^{*}$ & $\mid, 378^{n+4}$ &, $288^{*}$ & , $251^{*}$ & $\star, 352^{*}$ & $369^{*}$ &, $403^{*}$, &, $403^{n}$ & $483^{*}$ &, $453^{*}$ & $4,446^{m}$ & $0,357^{*}$ & $\mid, 383^{*}$ &, $428^{\circ}$ & $1,497^{7}$ &, 456 &, $410^{*}$ & $7,534^{*}$ &, $543^{*}$ &, $412^{*}$ & $\mid, 394^{*}$ &, 546 & $7,625^{*}$ & 1 & & \\
\hline 27. & ,491" &, $551^{*}$ &, $396^{*}$ & $4,470^{+*}$ & $392^{*}$ &, $518^{*}$ & $n, 387^{*}$ &, $503^{*}$ & $513^{*}$ &, $498^{\circ}$ & $560^{*}$ &, $531^{*}$ & 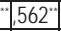 & $4,491^{*}$ & $4,473^{*}$ & ",634" & ,581 &, 595 &, $573^{*}$ & $602^{*}$ &, $590^{\circ}$ &, $474^{*}$ & $501^{*}$ & ,478, & $612^{* \prime}$ &., $431^{*}$ & 1 & \\
\hline 28 & , 371" & ,250* &, $322^{*}$ &, $452^{*}$ &, 184 &, $256^{*}$ & ${ }^{*}, 238^{*}$ & $345^{*}$ &, $345^{*}$ &, $329^{\prime \prime}$ & $373^{*}$ &, $530^{*}$ & ${ }^{*}, 510^{*}$ & ".,511* &, $451^{*}$ & $" 613^{*}$ & $.574^{4}$ &, $573^{*}$, &, $535^{n}$ &, $587^{*}$ &, $464^{*}$ & $357^{*}$ & $511^{*}$ & $0,511^{*}$, & ",581" &, $361^{*}$ &, 532 & 1 \\
\hline 29 , & $486^{4+4}$ & , 449* & $330^{*}$ & $4,477^{4}$ & $379^{*}$ & $4,474^{*}$ & $4,414^{*}$ & $498^{*}$ &, $560^{*}$ &, $547^{\circ}$ & $473^{4}$ & ,510* & "xat" & $558^{+4}$ &, $501 *$ & $7,651^{+4}$ & $1,640^{\circ}$ & $\frac{1,646^{m+},}{,}$ & 612 & $1,678^{*}$ & $=1,534^{*}$ & $386^{\prime \prime}$ & $616^{*}$ & $\mid, 513^{*}$ &, $716^{\prime \prime}$ & $4,480^{*}$ & $\pi, 599^{*}$ & " \\
\hline
\end{tabular}




\subsection{Factorial analysis of TCHAS}

The 29 items of the TCHAS (Parsons, 1973), which was adapted in Albanian were includes in a factorial analysis (Principal axis factoring with varimax-rotation), to identify possible factors associated with teaching anxiety.

It is proven if the data are suitable for conducting factorial analysis. The sample included in this study exceeds the minimum ratio 1 to 5 (5 persons for a variable), defined by Tabachnick and Fidell (2007). Index Kaiser-Meyer- Olkin for sample suitability for conducting factorial analysis was .93. This index is significantly higher than the minimum level .6, allowed to perform factorial analysis of defined by Kaiser (1974). Bartlett's Test, resulted statistically valid $(p<.05)$ (see Table 3). The data are suitable for conducting factorial analysis.

Table 3. KMO and Bartlett's Test

\begin{tabular}{|c|c|c|}
\hline \multicolumn{2}{|c|}{ Kaiser-Meyer-Olkin Measure of Sampling Adequacy. } & .930 \\
\hline & Approx. Chi-Square & 2514.361 \\
\hline \multirow[t]{2}{*}{ Bartlett's Test of Sphericity } & Df & 406 \\
\hline & Sig. & .000 \\
\hline
\end{tabular}

Factorial analysis of 29 items revealed three factors with a characteristic value (eigenvalue) over 1, which explain the respectively $57 \%, 7.7 \%$ and $3.7 \%$ of the variance. By inspection of the Scree Test (Catell, 1996), it was concluded a clear interruption after the second component (Figure 1).

Figure 1. Scree Test

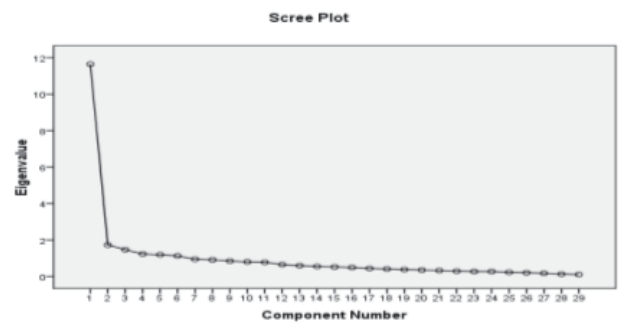

This was later supported by the results of the Parallel Analysis, which showed that there are only two factors with a characteristic value (eigenvalue) that exceed the corresponding values of the data matrix generated randomly for the same number of variables and one the same sample size ( 29 variables $\times 92$ respondents). Based on this, factorial analysis was repeated with two factors. It failed to point out the presence of the simple structure where the two components show a number of variables to strongly correlation with each of them.

So, the structure factor was not distinguishable and therefore, was judged the best solution for this sample teaching students was a single factor. For this reason, factorial analysis was conducted again and was requested to be extradited only one factor. This factorial analysis showed that, all items in the Teaching Anxiety Scale correlation with this single factor that explained $57 \%$ of variance with a characteristic value (eigenvalue) of the 16.52 (see Table 4).

Table 4. Total Variance Explained

\begin{tabular}{|c|c|c|c|c|c|c|}
\hline \multirow{2}{*}{ Component } & \multicolumn{4}{|c|}{ Initial Eigenvalues } & \multicolumn{3}{c|}{ Extraction Sums of Squared Loadings } \\
\cline { 2 - 7 } & Total & \% of Variance & Cumulative \% & Total & \% of Variance & Cumulative \% \\
\hline 1 & 16.523 & 56.976 & 56.976 & 16.523 & 56.976 & 56.976 \\
2 & 2.223 & 7.667 & 64.643 & & & \\
3 & 1.071 & 3.692 & 68.335 & & & \\
4 & .937 & 3.231 & 71.567 & & & \\
5 & .810 & 2.793 & 74.360 & & & \\
6 & .770 & 2.656 & 77.015 & & & \\
7 & .742 & 2.560 & 79.575 & & & \\
8 & .644 & 2.219 & 81.794 & & & \\
\hline
\end{tabular}




\begin{tabular}{|l|l|l|l|l|}
9 & .608 & 2.095 & 83.889 \\
10 & .508 & 1.751 & 85.641 \\
11 & .476 & 1.642 & 87.283 \\
12 & .425 & 1.466 & 88.749 \\
13 & .400 & 1.380 & 90.128 \\
14 & .353 & 1.216 & 91.345 \\
15 & .319 & 1.100 & 92.444 \\
16 & .269 & .928 & 93.372 \\
17 & .249 & .859 & 94.231 \\
18 & .228 & .786 & 95.017 \\
19 & .217 & .749 & 95.766 \\
20 & .210 & .725 & 96.491 \\
21 & .181 & .624 & 97.115 \\
22 & .160 & .553 & 97.667 \\
23 & .151 & .520 & 98.188 & \\
24 & .139 & .478 & 98.665 & \\
25 & .111 & .383 & 99.048 & \\
26 & .091 & .315 & 99.364 & \\
27 & .083 & .287 & 99.651 & \\
28 & .060 & .208 & 99.859 & \\
29 & .041 & .141 & 100.000 & \\
\end{tabular}

Extraction Method: Principal Component Analysis.

Correlations between the items and the factor ranging from 0.55 to 0.88 (see Table 5.)

Table 5. Component Matrix ${ }^{a}$

\begin{tabular}{|c|c|}
\hline & Component \\
\hline Item & 1 \\
\hline 1 & .746 \\
\hline 2 & .693 \\
\hline 3 & .585 \\
\hline 4 & .677 \\
\hline 5 & .695 \\
\hline 6 & .742 \\
\hline 7 & .722 \\
\hline 8 & .797 \\
\hline 9 & .810 \\
\hline 10 & .794 \\
\hline 11 & .809 \\
\hline 12 & .832 \\
\hline 13 & .883 \\
\hline 14 & .819 \\
\hline 15 & .795 \\
\hline 16 & .901 \\
\hline 17 & .872 \\
\hline 18 & .832 \\
\hline 19 & .786 \\
\hline 20 & .835 \\
\hline 21 & .738 \\
\hline 22 & .553 \\
\hline 23 & .730 \\
\hline 24 & .712 \\
\hline 25 & .764 \\
\hline 26 & .574 \\
\hline 27 & .710 \\
\hline 28 & .604 \\
\hline 29 & .729 \\
\hline
\end{tabular}

Extraction Method: Principal Component Analysis. a. 1 component extracted. 
Factorial analysis found that, items of the teaching anxiety scale yielded a single factor with an eigenvalue of 16.52 and the unifactor solution accounted for $57 \%$ of the total variance. A similar factorial with a single factor is identified as well and in other studies (Parsons, 1973; Albusaidi and Aldhafri, 2009).

Findings about the validity and reliability of the Teaching Anxiety Scale (Parson, 1973), Albanian version, are an added contribution to of the research literature in Albania. It is recommended to use this scale, in similar studies in Albanian reality.

\section{References}

Albusaidi, A. \& S. Aldhafri (2009). Validation of the Teaching Anxiety Scale (TCHAS 1-29). Paper presented at the 54th International Council on Education for Teaching, Muscat.

Al-Mehrzi, R., Al-Busaidi, S., Ambusaidi, S., Osman, M., Amat, M., \& Al-Ghafri, S., (2011). Path analysis of the effects of teaching attitudes and anxiety on pre-service teachers "efficacy beliefs". World Applied Sciences Journal 14 (Learning Innovation and Intervention for Diverse Learners): 52-59, 2011. ISSN 1818-4952

Cheung, H.Y. \& Hui, S.K.F. (2011) Teaching Anxiety amongst Hong Kong and Shanghai In-Service Teachers: The Impact of Trait Anxiety and Self-Esteem. Asia-Pacific Education Researcher, 20(2), 395-409

Field, A. (2005). Discovering statistics: Using SPSS for windows. London: SAGE Publications

Gregory, A. (1976), The effect of student teaching on the professional self-concept of student teachers - A study of student teachers in the professional program, Simon Fraser University.

Henson, Robin K. (2001) "Teacher Self-Efficacy: Substantive Implications and Measurement Dilemmas."

Kaiser, H. (1974). An index of factorial simplicity. Psychometrika, 39,31-6

Pigge, \& Marso, (1997). A seven year longitudinal multi-factor assessment of teaching concerns development through preparation and early teaching. Teaching and Teacher Education, 13(2), 225-235

Tabachnick, B.G. \& Fidell, L.S. (2007). Using multivariate statistics. (5th edition). Boston: Pearson Education

Tattersall, W. (1979) Patterns of change in teaching anxiety, professional self-concept and self-concept during an extended practicum: A study of student-teachers in Simon Fraser University's Education 405, Practicum.

Williams, L. S. (1991). The effects of a comprehensive eaching assistant training program on teaching anxiety and effectiveness. Research in higher education, vol. 32, no. 5, 585-598.

Woullard, R. (2003). A formative evaluation of a teacher education program at a rural community college focusing on the changes in the emotions, attitudes, and anxieties of pre-service teachers about their teaching careers. A Dissertation Submitted to the Faculty of Mississipi State University. 